\title{
The Research of Database Principle Experimental Teaching Mode based on "SPOC+CDIO"
}

\author{
Ping $\mathrm{Li}^{1, \mathrm{a}}$, Hong $\mathrm{Wu}^{1, \mathrm{~b}}$ and Jing Dong ${ }^{1, \mathrm{c}}$ \\ ${ }^{1}$ Department of Information Engineering, Qujing Normal University, Qujing, 655011, China \\ ajujncliping@163.com, b275060130@qq.com, ${ }^{c} 38831642 @ q q . c o m$
}

Keywords: SPOC; CDIO; Database principle experiment

\begin{abstract}
This paper analyzes the problems existing in the practice link of the database principle, and creatively puts forward the teaching mode of introducing SPOC+CDIO into the practice link of the database principle. This paper studies the teaching design and teaching operation from the aspects of simulation practice and independent design.
\end{abstract}

\section{Introduction}

With the continuous emergence of new computer technology, the database principle course has complements new teaching contents in order to meet the needs of database technology development. However, the teaching hours of database principle course are limited. There is a contradiction between limited class hours and growing teaching contents. How to make good use of teaching facilities to organize a good teaching mode, improve teaching quality and expand teaching contents in a limited time is a challenge for every teacher.

\section{SPOC}

SPOC is an improved MOOC teaching model, which combines classroom teaching and online teaching, and the form of class is carried out in a combination of face-to-face and online self-study. [1] The students of SPOC are mostly college students who are learning specific courses. They have the same basis and clear goals. The number of classroom teaching is generally the number of students in a natural class, which can improve the guiding role of teachers and improve students' knowledge and participation. [2]Thus, the use of SPOC to customize the network auxiliary teaching model that meets the requirements of the course can well reflect the curriculum characteristics. Experiment teaching of computer software courses based on SPOC and multimedia network classroom. [3]

\section{CDIO}

CDIO is an advanced model of engineering education, with project development as the carrier, through the process of conception (Conceive), design (Design), implementation (Implement) and operation (Operate), let the students participate in the whole process of the analysis from the needs of the project to the implementation.[4] It emphasizes students' hands-on practice and increases students' practical experience.

\section{The Characteristics and Present Situation of the Course of Database Principle}

The database principle course is strong in theory, practice and engineering. Teaching involves experiments in database theory and database application technology. Theoretical knowledge is abstract, which is the theoretical basis of database application technology. The experiment teaching is mainly to promote the students' understanding of the principle, to cultivate the students' ability to develop the database application system, and to have the preliminary experience in the development of the database. But in the actual teaching, there are students who can understand the teacher's demonstration, but can not face the problems of the real world freely, and design and implement a 
database application system. The reasons for the analysis show that the students do not understand the principles of database sufficiently, and their abilities of practice are weak, so they do not form the thinking of database design. The fundamental reason for teaching lies in the limited experimental teaching mode of "demonstration" + "verification". In the process of experiment teaching of database principle, how to train students' thinking of database design and cultivate students' experience in engineering has become a problem that needs to be solved in the experiment teaching of database principle.

\section{The Experimental Teaching Model of CDIO+SPOC}

Following the educational concept of CDIO, taking the case and the comprehensive experiment as the main line, the skills that the students should master, the quality of engineering and the thinking of calculation are run through the experimental teaching process. SPOC teaching platform is used to design teaching mode and evaluation method to improve the quality of experimental teaching.

The experimental teaching goal of the course of database principle is set up to train the students' ability to conceive, design, realize and operate the database application system, and form the calculation thinking. [5]In order to conform to the cognitive process of learning, the experimental teaching link is divided into two parts. The first step is the simulation experiment under the demonstration case; the second is the independent design experiment.

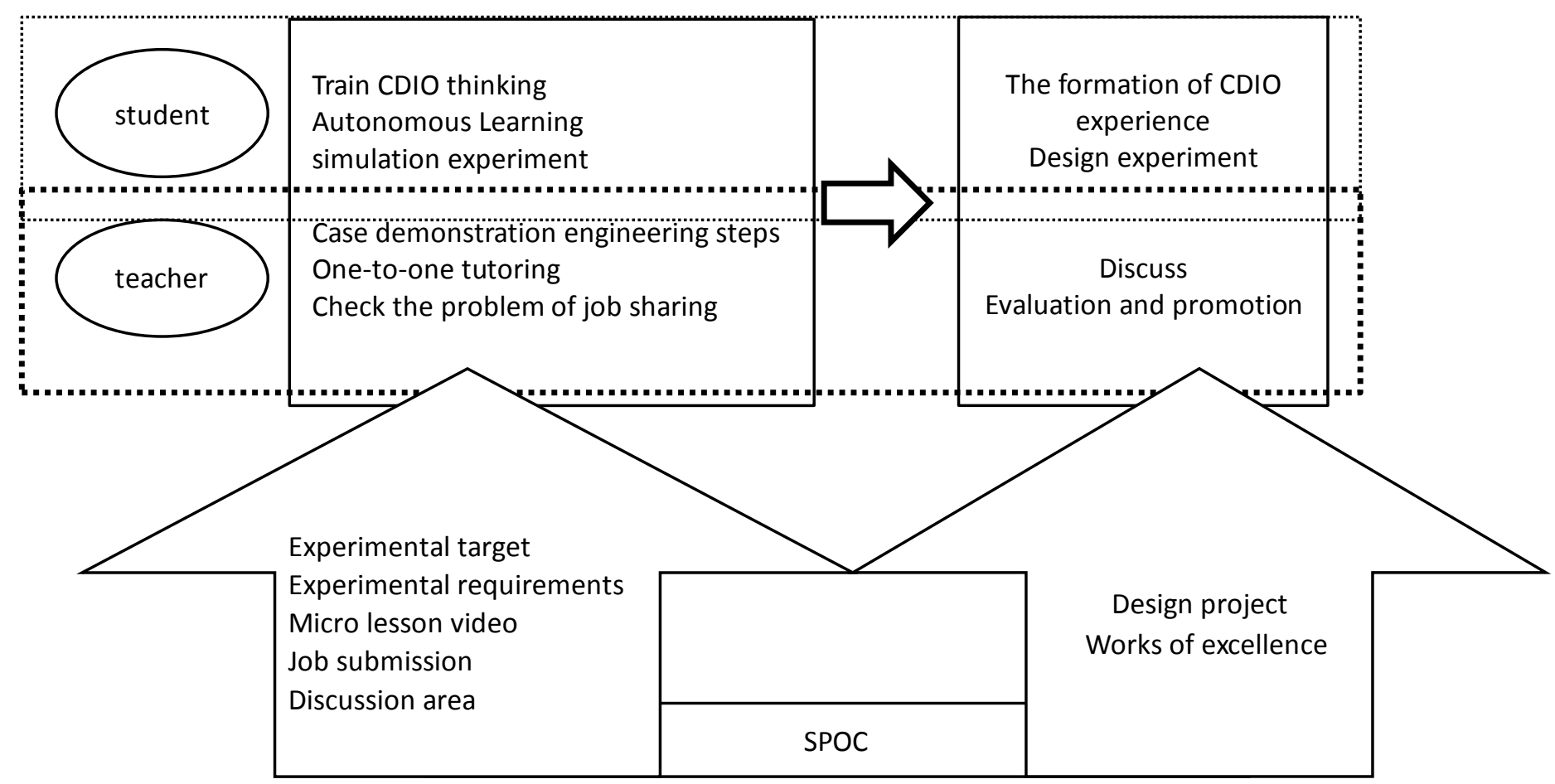

Figure 1. Finite The experimental teaching model of CDIO+SPOC

Simulation Experiment Link. The teacher chooses a case, which is divided into 4 parts[6]: demand analysis, database design, database implementation and operation, and the experiment task is decomposed to each part, which is as follows:

The requirement analysis part is a conceptual process. By analyzing the user's needs for system functions, we conceive the data items that the database needs to store. It uses data flow graph and data dictionary to reduce user needs, abstracts data flow and processing actions, and expresses data items, data structures, data storage, etc.

The design part is a process of abstract abstraction of the real world, a conceptual model in the information world, and a logical model and a physical model in the computer world. The conceptual model is designed by the abstract method of aggregation and generalization, and the normalized 
standard is decomposed by recursive thinking. In the physical model design stage, the spatial efficiency and time efficiency of index are considered with compromise thought.

The realization part realizes the result of the design phase by the way of programming, and creates the corresponding database, table, view, trigger, stored procedure and cursor with SQL statement, and realizes the idea of computer automatic execution.

The operation part uses advanced programming language to run database application system, and further realizes the idea of automatic execution. Redundant technology is used to build backup copies and logs of database, and realize the idea of redundancy recovery.

Through the above part of the study, let the students understand the steps of the database application system development engineering, understand the relevance of the related courses, and initially form the calculation thinking. Teaching research of database based on the cultivation of Computational Thinking Ability. [7]

There are 2 problems in the development of this link: there are more knowledge to be developed, such as data flow graph, database modeling tool and data storage method, and so on; the steps of the experiment are not exactly in accordance with the order of the textbooks. Therefore, we should use classroom communication and SPOC autonomous learning to combine teaching. This link is divided into 2 stages: perceptual knowledge before class and analog communication in class. [8]

The purpose of the perceptual knowledge stage is to arouse the students' attention to the content of the experiment, to understand the basic steps of the experiment, to master the grammatical structure of the basic sentences, to make clear the emphasis of the experiment and to confuse the confusing knowledge points, and to supplement the knowledge points outside the teaching materials. For this purpose, teachers release SPOC experimental objectives, experimental requirements, micro class videos and so on. In the pre class guidance, students watch SPOC videos, learn the corresponding content autonomously, find problems, issue problems in the SPOC discussion area, and exchange and help each other.

On the basis of perceptual knowledge, the purpose of the analog communication stage in class is to solve the problem of problem internalization knowledge. [9] In the experimental class, teachers focus on the problems in the discussion area, and carry out one to one personalized guidance according to the different situations of students. Students can learn the forgotten knowledge by SPOC platform, complete the experiment assignments in the hall, and submit them through SPOC. The teacher examines the student's task completion through the experiment homework, finds out the common problems and comments in the class.

Because students are prepared to take the initiative to consider the experimental steps, participate in the discussion, greatly improving the quality of experimental teaching. Repeated learning process further improves students' proficiency in experimental procedures.

Independent Design Experiment. On the basis of simulation experiments, the design process of students needs further development from perceptual knowledge to rational knowledge. Therefore, this link needs to be further understood and applied in practice to develop the truth, so that students can internalize the design process of the database. Teaching design of database based on cognitive law. [10]

The students complete the comprehensive experiment in the form of group cooperation. In the design process, the experimental content is decomposed into sub tasks, and the design documents at each stage are submitted to demonstrate the final results. Let the students who need further study go to the training base outside the school to experience the project development process. The whole process reproduces the $\mathrm{CDIO}$ process and improves computational thinking.

This link is divided into 3 stages: independent design, evaluation promotion and work study combination.

In the independent design stage, teachers upload experimental subjects to SPOC platforms, and students choose topics or themes independently. The teacher instruct or urge the teams to complete the design task through discussion and inspection. And upload excellent works to SPOC platform for you to learn. Experience in student design process can also be uploaded to the SPOC platform for you to share. 
The evaluation and promotion stage is the subject of each group's responsibility. It expounds the thinking and methods of solving the problems. The teachers give analysis, induction and summary to make the students rebuild the process of database design. Let students learn from imitation to find problems and explore solutions to problems. And enable students to have the confidence to complete the database application system development and the sense of achievement gained in the evaluation.

In the process of combining learning and learning, the students who need to study deeply, to some training companies to participate in the research and development of the actual project database, and continue to improve the development ability of the database application system.

\section{Conclusion}

The student based teaching concept, taking into account the students' perception, conforms to the students' self construction process and knowledge law, and has trained the students' ability to study and explore independently. The students' experimental results should not only assess the students' mastery of basic skills and independently design the CDIO project, but also examine the situation of students' video learning on the SPOC and the speech in the discussion area, improve the students' participation in the study and stimulate the students' interest in learning.

Acknowledgements "Database principle" of university-level high-quality courses of QuJing normal university item number: JPKC2016005

\section{References}

[1] Y.D. Hu and Z.Y. Gao: The Chinese Journal of ICT in Education, (2017) No.2,p.28(In Chinese)

[2] A. Fox: Communications of the ACM, Vol. 56 (2013) No.12, p.38

[3] D.H. Zhang and X.M. Zhu: Experimental Technology and Management, Vol. 34 (2017) No.8, p.195(In Chinese)

[4] Y.C. Zhang: Agriculture Network Information, (2016) No.9,p.125(In Chinese)

[5] X. Ye, R. Luo and H.L. Li: Computer Education, (2017) No.1,p.95(In Chinese)

[6] W.G. Li and M.L. Sun: Computer Education, (2017) No.12,p.65(In Chinese)

[7] C.L. Cheng, S.X. Zhang and L. Cheng: China Electric Power Education, (2012) No.8,p.81(In Chinese)

[8] Y.Q. Zhao: Computer Education, (2017) No.8,p.125(In Chinese)

[9] Y. Zhang: Computer Education, (2017) No.1,p.131(In Chinese) 